\title{
The Association of Gap Junctions with Large Particles in the Crypt Epithelium of the Rat Small Intestine*
}

\author{
Katsuko KataokA ${ }^{1}$, Junko Tabata ${ }^{2}$, Masao Yamamoto ${ }^{1}$ and Toshihide Toyota ${ }^{1}$ \\ Department of Anatomy ${ }^{1}$, Hiroshima University School of Medicine, Hiroshima and Biwako-Yoikuin Hospital ${ }^{2}$, Otsu, Japan
}

Received August 15, 1988

Summary. Intercellular junctions in the epithelium of the rat small intestine were studied by the freezefracture method. Gap junctions were found between columnar cells of the crypt far more frequently than between absorptive cells of the villus. In addition, in the crypt, large particles 11 to $13 \mathrm{~nm}$ in diameter were often associated with the gap junction which primarily consisted of usual gap junctional particles 8 to $9 \mathrm{~nm}$ in diameter. Both the usual and large particles possessed a central pit.

The intestinal crypt is the site of epithelial cell proliferation and differentiation in the process of physiological cell renewal. The predominant presence of gap junctions in this region suggests that they play a certain role in the proliferation and differentiation of crypt columnar cells. Further studies are required to elucidate the nature of the large particles, a precursor of typical connexons and/or a functionally different gap junction.

Gap junctions have been considered the site of intercellular communication in providing channels for the passage of ions and small molecules between neighboring cells (reviewed by STAEHELIN, 1974; PERACCHIA, 1980; Gilula, 1985). STAEHELIN (1972) reported three types of gap junctions in the epithelium of the rat small intestine: type-I gap junctions consisting of 8 to 9 -nm particles; type-II gap junctions, consisting of 10- to 11-nm particles; and type-III gap junctions, consisting of small rectilinear arrays of very small particles. However, STAEHELIN himself (1974) denied the existence of type-III gap junctions because of their presence on membranes of striated muscle cells which do not form gap junctions.

STAEHELIN $(1972,1974)$ described the localization of type-I and -II gap junctions as being on the intestinal epithelium, an observation which has given rise to the misconception that two types of gap junctions are present between absorptive cells of intestinal villi. Precise examination in the present study revealed that type-I gap junctions were found far more frequently in the intestinal crypt than in the villus and that type-II gap junctions were confined to the crypt.

\section{MATERIALS AND METHODS}

Normal adult Wistar rats were used for this study. Under Nembutal anesthesia, the animals were perfused with $2.5 \%$ glutaraldehyde in $0.1 \mathrm{M}$ cacodylate buffer $(\mathrm{pH} 7.4)$ from the left ventricle of the heart. The proximal part of the small intestine (the duodenum and jejunum) was minced into small pieces and then immersed in the same glutaraldehyde fixative at least overnight at $4^{\circ} \mathrm{C}$.

After immersion in $30 \%$ glycerin solution, the pieces of tissue were placed on a copper stage cooled by liquid nitrogen, and fractured at $-110^{\circ} \mathrm{C}$ in a JEOL JFD-7000 or an EE-FED-B freeze-fracture device. Platinum-carbon replicas were made without etching. They were cleaned in filtered commercial bleach, mounted on copper grids and examined in a Hitachi H-300 or a HU-11DS electron microscope.

\footnotetext{
*This study was supported by Grants-in-Aid for Special Project Research and for Scientific Research from the Ministry of Education, Science and Culture, Japan.
} 


\section{RESULTS}

As in other animals, the mucosa of the rat small intestine has numerous intestinal villi and crypts of Lieberkühn. The simple columnar epithelium of the villus consists of absorptive cells, some goblet cells and a few endocrine cells. The epithelium of the crypt is also simple columnar and contains columnar cells, goblet cells, Paneth cells and endocrine cells. Each type of cell could be easily identified on freeze-fracture replicas by their cytoplasmic fine structures, which have been well established through electron-microscopic observation of thin sections (TRIER, 1968; KATAOKA, 1970 ; Cheng and Leblond, 1974a, b).

Columnar cells of the intestinal crypt were tall and pyramidal in shape with a basally situated nucleus (Fig. 1). Some microvilli were projected into the lumen of the crypt. Apical vesicles, a few profiles of the endoplasmic reticulum, some mitochondria and a small Golgi complex were found in the apical and supranuclear cytoplasm.

On the lateral cell surface, crypt columnar cells were mutually joined by an adluminal tight junction and scattered gap junctions. Gap junctions were round, with large ones usually located in the basal part of the lateral plasmalemma or at the level of the cell nucleus. On the P-face, the gap junction was seen as an aggregation of intramembranous particles, which were usually 8 to $9 \mathrm{~nm}$ in diameter and packed into a disordered array at an average center-to-center distance of $10 \mathrm{~nm}$ (Fig. 2). In addition, large particles 11

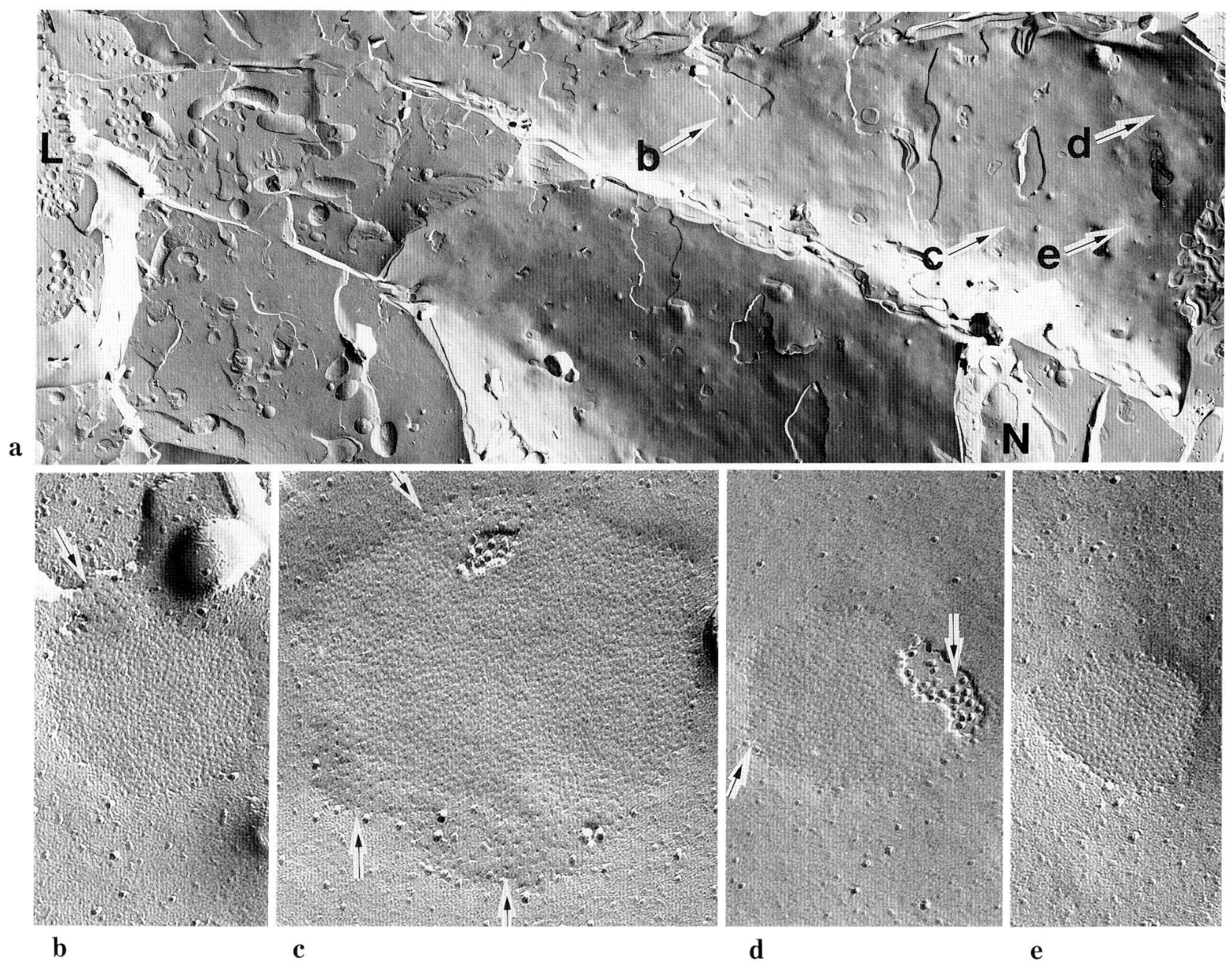

Fig. 1. Gap junctions between columnar cells of the intestinal crypt. a. A low magnification showing the distribution of gap junctions (arrows $b-e$ ), which are enlarged in $\mathbf{b}-\mathbf{e}$, respectively. $L$ lumen of the crypt, $N$ nucleus. $\times 7,000$. b-e. Higher magnifications of the gap junctions. Arrows large particle domains. $\times 100,000$ 
to $13 \mathrm{~nm}$ in diameter were often seen. These large particles tended to arrange themselves in a hexagonal array at an average center-to-center distance of $20 \mathrm{~nm}$. Both the usual and large particles had a central pit. One to three domains of large particles were often associated with the periphery of the gap junctional profile. Occasionally, the domain of the large particles was inserted between aggregations of normal-sized particles. A few solitary large particles, 10 to $13 \mathrm{~nm}$ in diameter, were scattered at the rim of the gap junction or embedded in the interior of the gap junction.

On the E-face, usual gap junctions were seen as irregularly packed pits at an average center-to-center distance of $10 \mathrm{~nm}$ (Fig. 1). The domain of the large particles was represented by hexagonal arrays of pits with an average center-to-center spacing of $20 \mathrm{~nm}$.

Near the opening of the crypt, columnar cells acquired more developed microvilli and cytoplasmic membranous organelles than did typical columnar cells of the crypt. This region between the crypt and villus is here referred to as the "transitional region." Gap junctions were often seen, but the association of large particles between columnar cells in the transitional region could not be demonstrated.

Absorptive cells on the villus were tall and columnar. The nucleus was located at the middle level of the cell height. The apical cell surface projected numerous microvilli to form the brush border (Fig. 3). Many elements of the endoplasmic reticulum, a good number of mitochondria and a large Golgi complex were seen from the apical to the supranuclear cytoplasm. Mitochondria were also accumulated in the infranuclear region.

On the lateral cell surface, absorptive cells were mutually joined by the tight junction near the intestinal lumen. Gap junctions were occasionally found, though it was much harder to find gap junctions in the villus than in the crypt. Large gap junctions, over $0.5 \mu \mathrm{m}$ in diameter, more elliptical than round in many cases, were located on the lateral plasmalemma about the level of the nucleus. Smaller gap junctions were

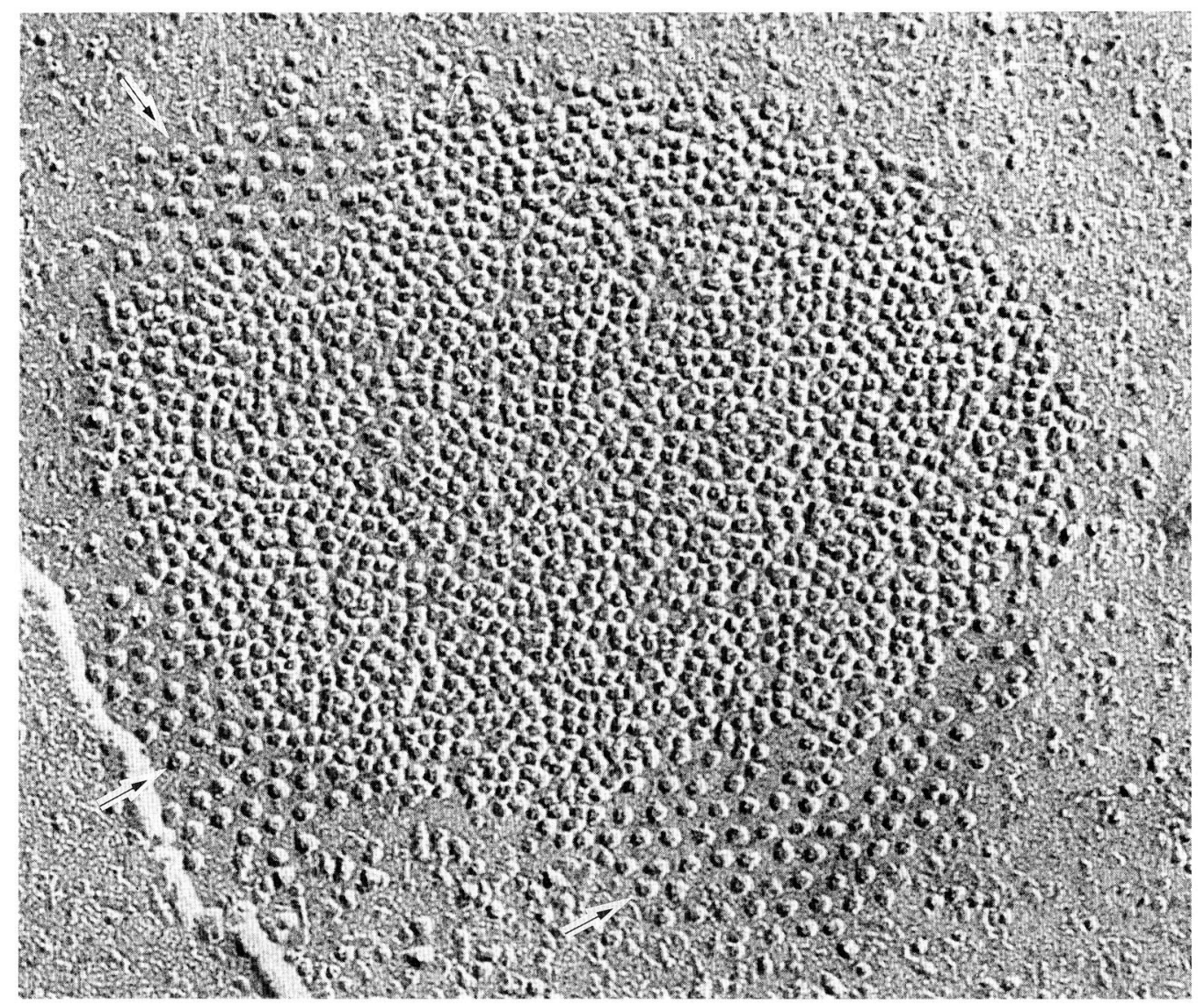

Fig. 2. Large particles (arrows) are associated with a gap junction in the crypt epithelium. A central pit is seen on both the usual and large particles. $\times 170,000$ 


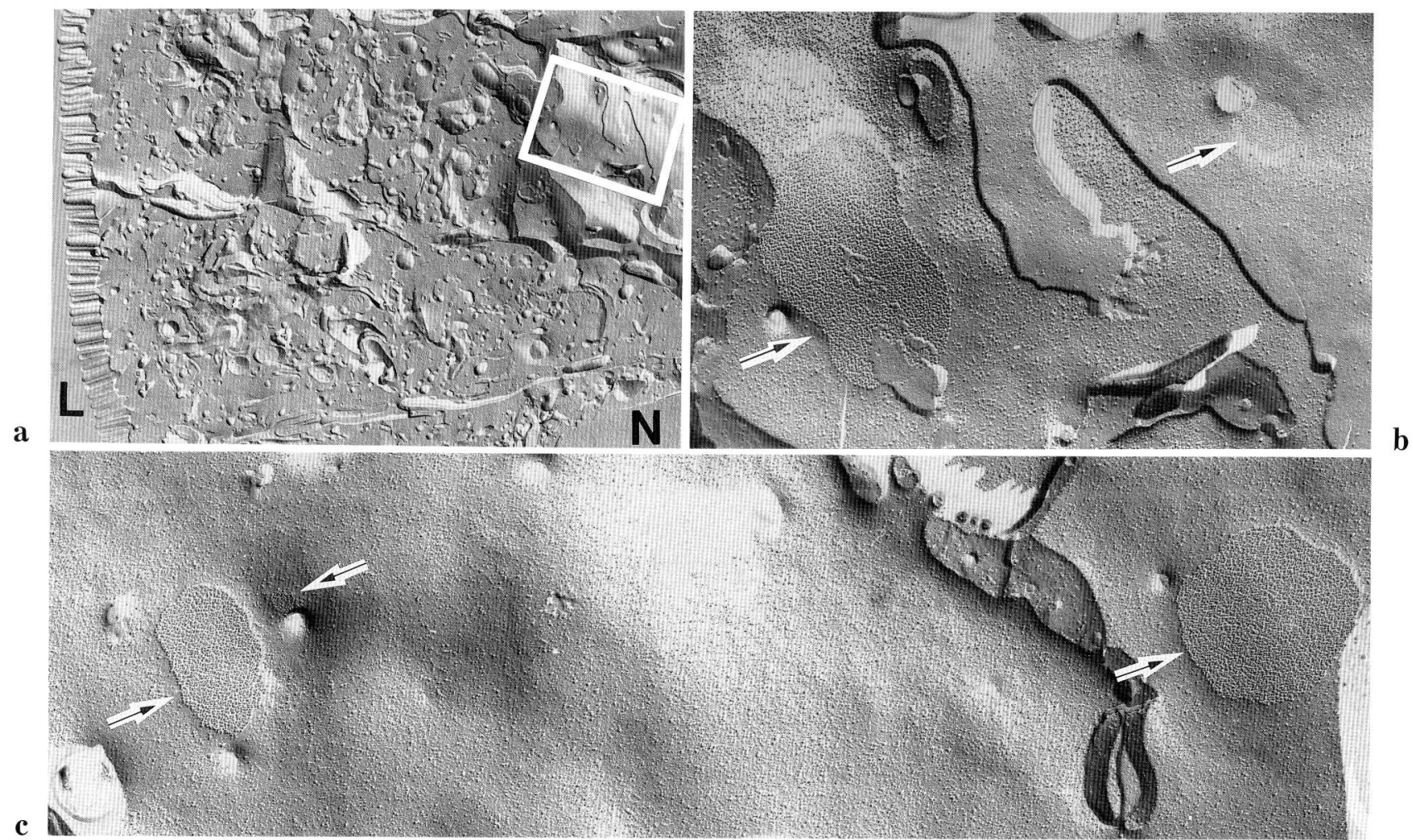

Fig. 3. Gap junctions (arrows) between absorptive cells in the villous epithelium are not associated with large particles. The enclosed area in $\mathbf{a}$ is enlarged in $\mathbf{b}$. $L$ intestinal lumen, $N$ nucleus. $\mathbf{a}: \times 6,500, \mathrm{~b}, \mathbf{c}: \times 30,000$

present anywhere on the lateral cell surface. Neighboring absorptive cells were interconnected by two or three large gap junctions in some cases, but gap junctions, even small ones, could not be recognized in many others. The cause of this difference was not clear. The association of large particles was not evidenced with the gap junction in the villous epithelium.

The numbers of gap junctions observed between columnar cells of the crypt, between columnar cells of the transitional region from the crypt to the villus and between absorptive cells of the villus are listed in Table 1.

Goblet cells were identifiable in both crypts and villi by cell shape, abundant parallel arrays of the endoplasmic reticulum, a large Golgi complex and mucous granules. Paneth cells were identified in the crypt base by abundant parallel arrays of the endoplasmic reticulum and large secretory granules. Endocrine cells were occasionally identified by their small secre-

Table 1. Number of gap junctions observed

\begin{tabular}{lcrr}
\hline & Crypts & $\begin{array}{c}\text { Transitional } \\
\text { regions }\end{array}$ & Villi \\
\hline Total number of gap junctions & 1021 & 192 & 117 \\
Gap junctions with large particles & 283 & 0 & 0 \\
Gap junctions without large particles & 663 & 183 & 110 \\
Unknown* & 75 & 9 & 7 \\
\hline
\end{tabular}

Gap junctions less than $0.1 \mu \mathrm{m}$ in diameter were not counted. They were rarely associated with large particles.

*The association of large particles was not determined, the main cause for this being that the whole area of the gap junction was not observed. 
tory granules in the basal cytoplasm. These three types of cells were joined with neighboring cells by tight junctions, but gap junctions were not observed.

\section{DISCUSSION}

The usual gap junction and the domain of large particles in the present study correspond to the type-I and -II gap junctions of STAEHELIN (1972, 1974), respectively.

The epithelial cells of the small intestine belong to a renewing population. They arise by mitosis in the lower two thirds of the intestinal crypt (generative zone) and migrate along the villous wall to the tip, where they are extruded into the intestinal lumen (Messier and Leblond, 1960; KATAOKa, 1970; ChenG and LEBLOND, 1974a, b). Columnar cells of the crypt have been grouped into the following three categories (CHENG and LEBLOND, 1974a, b; BJERKNES and CHENG, 1981): a) Undifferentiated stem cells are present in the crypt base, proliferate and are able to differentiate into absorptive, goblet, Paneth and endocrine cells; b) mid-crypt columnar cells are not only proliferative but also certain to differentiate to absorptive cells; c) crypt-top columnar cells do not divide but continue to differentiate into absorptive cells. Undifferentiated stem cells and mid-crypt columnar cells are brought together in the population of crypt columnar cells in the present study, since these two groups of columnar cells could be hardly classified by a freeze-fracture study. The cells, called columnar cells in the transitional region in the present study, mostly correspond to crypt-top columnar cells. From these, it is concluded that undifferentiated cells and proliferative immature absorptive cells are connected by well developed gap junctions accompanying the large particles. Non-proliferative immature absorptive cells at the top of the crypt are still interconnected by well-developed gap junctions but not by large particles. The presence of gap junctions has also been proved by intercellular transfer of Lucifer yellow between columnar cells at all levels of the intestinal crypt (BJERKNES et al., 1985).

On the other hand, gap junctions were only occasionally seen between mature absorptive cells of the villus in the present study. This coincides with the brief description made by BJERKNES et al. (1985), who found only small gap junctions between absorptive cells of the mouse small intestine. In the rat small intestine, there is a contradiction between the descriptions by FRIEND and Gilula (1972) and by STAEHELIN (1972, 1974): the former only cited a personal communication on the presence of diminutive gap-junctional plaques but did not confirm it by themselves, while the latter showed large gap junctions. It is speculated from the present results that FRIEND and GILULA (1972) observed the villous epithelium while STAEHELIN $(1972,1974)$ observed the crypt epithelium.

Intercellular communication mediated by gap junctions has been considered essential for the regulation of growth and differentiation (reviewed by GILULA, 1985). During ontogenesis, the rapid enlargement of gap junctions occurs simultaneously with the morphological and functional differentiation of the otocyst sensory epithelium (GINZBERG and GILULA, 1979), adrenocortical cells (DECKER, 1981) and pancreatic acinar cells (YAMAMOTO and KATAOKA, 1985). It was also reported that gap junctions enlarged in the duodenal epithelium of chick embryos from Days 6 to 21 of incubation (OKAмоTO and IsHIMURA, 1978). The present study revealed frequent gap junctions between immature absorptive cells in the crypt but only occasional ones between mature absorptive cells in the villus. These findings suggest that gap junctions in the intestinal epithelium are mostly transient structures that play an important role in cell proliferation and absorptive cell differentiation rather than in maintaining the function of mature absorptive cells. The role of gap junctions persisting at times between mature absorptive cells is not known.

The present study revealed large particles associated with gap junctions interconnecting columnar cells of the crypt. Of particular interest is the fact that gap junctions with large particles join cells in less mature stages in absorptive cell differentiation than gap junctions without large particles, as discussed above. The appearance of particles larger than typical connexons has been noted during gap junctional development in various cell types including epiblasts of the chick embryo (REVEL et al., 1973), neuroepithelial cells (DECKER and FRIEND, 1974), lutein cells during pregnancy (ALBERTINI and ANDERSON, 1975), ependymal cells (DECKER, 1976), otocyst sensory epithelial cells (GINZBERG and GILULA, 1979), pancreatic acinar cells (YAMAMOTO and KATAOKA, 1985) and columnar cells in the intestinal crypt (the present study). JOHN SON et al. (1974) observed the reaggregation of dissociated Novikoff hepatoma cells and found "formation plaques" which appeared prior to gap-junction formation and were characterized by the presence of 9- to 11-nm particles. From these facts, many authors have suggested that the large particle represents a form of a gap-junction precursor (JOHNSON et al., 1974; AlBertini and ANDERSON, 1975; DECKER, 1976; 
YAMAMOTO and KatAOKA, 1985). STAEHELIN (1972), who first discovered large particles, mentioned the possibility of the presence of intercellular channels having different sizes and/or different inner surface properties. If the central pit observed on the P-face of the large particle, which is 2 to $4 \mathrm{~nm}$ in diameter instead of the 1 to $2 \mathrm{~nm}$ pit of usual connexons (YAMAMOTO and KATAOKA, 1985), actually represents a communication channel, then the large particle must allow the intercellular passage of larger molecules and/or larger amounts of molecules than the usual connexon. The two possible natures of the large particles, a precursor of the connexon and an intercellular channel different from that mediated by the usual connexon, may not necessarily contradict each other. Studies on the intercellular passage of molecules of various sizes may shed light on the nature and function of the large particles.

Acknowledgements. The authors are grateful to Mr. Kenji JoJI, Translation Section, Radiation Effect Research Foundation, Hiormoshima, Japan, for his assistance in preparing the manuscript.

\section{REFERENCES}

Albertini, D. E. and E. Anderson: Structural modifications of lutein cell gap junctions during pregnancy in the rat and the mouse. Anat. Rec. 181: 171-194 (1975).

BJerknes, M. and H. Cheng: The stem-cell zone of the small intestinal epithelium. III. Evidence from columnar, enteroendocrine, and mucous cells in the adult mouse. Amer. J. Anat. 160: 77-91 (1981).

BJERKnes, M., H. Cheng and S. ErLandsen: Functional gap junctions in mouse small intestinal crypts. Anat. Rec. 212: 364-367 (1985).

Cheng, H. and C. P. Leblond: Origin, differentiation and renewal of the four main epithelial cell types in the mouse small intestine. I. Columnar cell. Amer. J. Anat. 141: 461-480 (1974a).

: Origin, differentiation and renewal of the four main epithelial cell types in the mouse small intestine. V. Unitarian theory of the origin of the four epithelial cell types. Amer. J. Anat. 141: 537-562 (1974b).

DECKER, R. S.: Hormonal regulation of gap junctional differentiation. J. Cell Biol. 69: 669-685 (1976).

-: Gap junctions and steroidogenesis in the fetal mammalian adrenal cortex. Devel. Biol. 82: 20-31 (1981).

DECKER, R. S. and D. S. Friend: Assembly of gap junctions during amphibian neurulation. J. Cell Biol. 62: 32-47 (1974).

Friend, D. S. and N. B. Gilula: Variations in tight and gap junctions in mammalian tissues. J. Cell Biol. 53: 758-776 (1972).
Gilula, N. B.: Gap junctional contact between cells. In: (ed. by) G. M. EDELMAN and J.-P. ThIERY: The cell in contact. Adhesions and junctions as morphogenetic determinants. A Neurosciences Institute Publication, John Wiley \& Sons, New York, 1985 (p. 395-409).

GinzBerg, R. D. and N. B. Gilula: Modulation of cell junctions during differentiation of the chicken otocyst sensory epithelium. Devel. Biol. 68: 110-129 (1979).

Johnson, R., M. Hammer, J. Sheridan and J.-P. REVEL: Gap junction formation between reaggregated Novikoff hepatoma cells. Proc. Nat. Acad. Sci. USA 71: 4536-4540 (1974).

KАTAокA, K.: The fine structure of the proliferative cells of the mouse intestine as revealed by electron microscopic autoradiography with ${ }^{3} \mathrm{H}$-thymidine. Z. Zellforsch. 103: 170-178 (1970).

Messier, B. and C. P. Leblond: Cell proliferation and migration as revealed by radioautography after injection of thymidine- $\mathrm{H}^{3}$ into male rats and mice. Amer. J. Anat. 106: 247-285 (1960).

OKамото, H. and K. IshimuRa : Freeze-etching observation on the development of intercellular junctions of the duodenal epithelial cells in the chick embryo. Arch. Histol. Jap. 41: 325-337 (1978).

Peracchia, C.: Structural correlates of gap junction permeation. Int. Rev. Cytol. 66: 81-146 (1980).

Revel, J.-P., P. YIP and L. L. Chang: Cell junctions in the early chick embryo-A freeze etch study. Devel. Biol. 35: 302-317 (1973).

STAEhelin, L. A.: Three types of gap junctions interconnecting intestinal epithelial cells visualized by freezeetching. Proc. Nat. Acad. Sci. USA 69: 1318-1321 (1972).

- Structure and function of intercellular junctions. Int. Rev. Cytol. 39: 191-283 (1974).

TriER, J. S.: Morphology of the epithelium of the small intestine. In: (ed. by) C. F. CODE: Handbook of physiology, Sect. 6: Alimentary canal, Vol. 3: Intestinal absorption. American Physiological Society, Washington DC, 1968 (p. 1125-1175).

Yамамото, M. and K. KATAOKA: Large particles associated with gap junctions of pancreatic exocrine cells during embryonic and neonatal development. Anat. Embryol. 171: 305-310 (1985).

\author{
Prof. Katsuko KataoKa \\ Department of Anatomy \\ Hiroshima University School of Medicine \\ 1-2-3 Kasumi, Minami-ku \\ Hiroshima, 734 Japan \\ 片岡勝子 \\ 734 広島市南区霞 1-2-3 \\ 広島大学医学部 \\ 解剖学第二講座
}

